\title{
La producción de Manolo Prieto para la revista Novelas y Cuentos. Un archivo documental imprescindible del diseño gráfico de nuestro país
}

\begin{abstract}
Resumen
La colección de portadas de Novelas y Cuentos — de la editorial Dédalo— realizadas por Manolo Prieto (Puerto de Santa María, Cádiz 1912-Madrid 1991) es una extensa producción gráfica. Más de 600 portadas diseñadas a lo largo de 17 años. Un prontuario de recursos gráficos llevado a cabo entre la década de los años 40 a los 60, un periodo clave en el desarrollo del diseño gráfico en España. Este artículo incorpora un nuevo documento en la investigación y catalogación de esta producción que modificó sustancialmente el método de trabajo de Manolo Prieto.
\end{abstract}

Palabras clave: Manolo Prieto, diseño gráfico, diseño editorial, ilustración.

Manolo Prieto's producción for the magazine Novelas y Cuentos.

A documentary archive essential in spanish graphic design

\section{Abstract}

The front covers collection of Novelas y Cuentos, Dédalo publishing house, made by Manolo Prieto (Puerto de Santa María, Cádiz, 1912 - Madrid,1991) is an extensive graphic production. More than 600 front covers designed along 17 years. A compendium of graphic resources performed in the decade between the 40 to 60's, a key period in the field of graphic design in Spain. This article incorporates a new document to the research and cataloging process of this production, which substantially modified Manolo Prieto's working process.

Keywords: Manolo Prieto, graphic design, editorial design, illustration.

\footnotetext{
La inteligencia humana

es un proceso no solo de percepción,

sino también de selección.
}

Ken Robinson

La catalogación y análisis del total de las portadas realizadas por Manolo Prieto para la revista Novelas y Cuentos ha supuesto un trabajo de gran complejidad debido a tres razones principales: 
por un lado, la envergadura de la producción, un total de 618 portadas editadas en 17 años; de otra parte, la existencia de portadas no firmadas de difícil atribución (fueron varios los ilustradores que trabajaron para esta editorial) y, finalmente, la extensa documentación conservada por la Fundación Manolo Prieto, fuente principal de este archivo. Ha sido esencial, en este trabajo de investigación la colaboración de su presidente, Manolo Prieto (hijo). Este trabajo de doctorado ha permitido la recopilación, ordenación y clasificación de todas las portadas, acompañadas de los bocetos, artes finales y pruebas de imprenta conservadas ${ }^{1}$ (fig. 1).

Incluimos en este artículo una última portada, localizada con posterioridad a la lectura de esta tesis y que hemos sumado al archivo documental.

Nos enfrentamos -en esta investigación - a varias tareas ineludibles en el proceso de catalogación de toda esta documentación. En primer lugar, la revisión de todos los bocetos y pruebas de imprenta ¿de cuántos disponíamos? ¿cuáles correspondían a los trabajos para Novelas y Cuentos?, ¿cómo abordar la clasificación de estos bocetos y pruebas de imprenta con las portadas disponibles? Una vez recopilado todo este material gráfico establecimos un sistema de catalogación de cada una de las portadas con sus correspondientes bocetos y pruebas de imprenta (fig. 2).
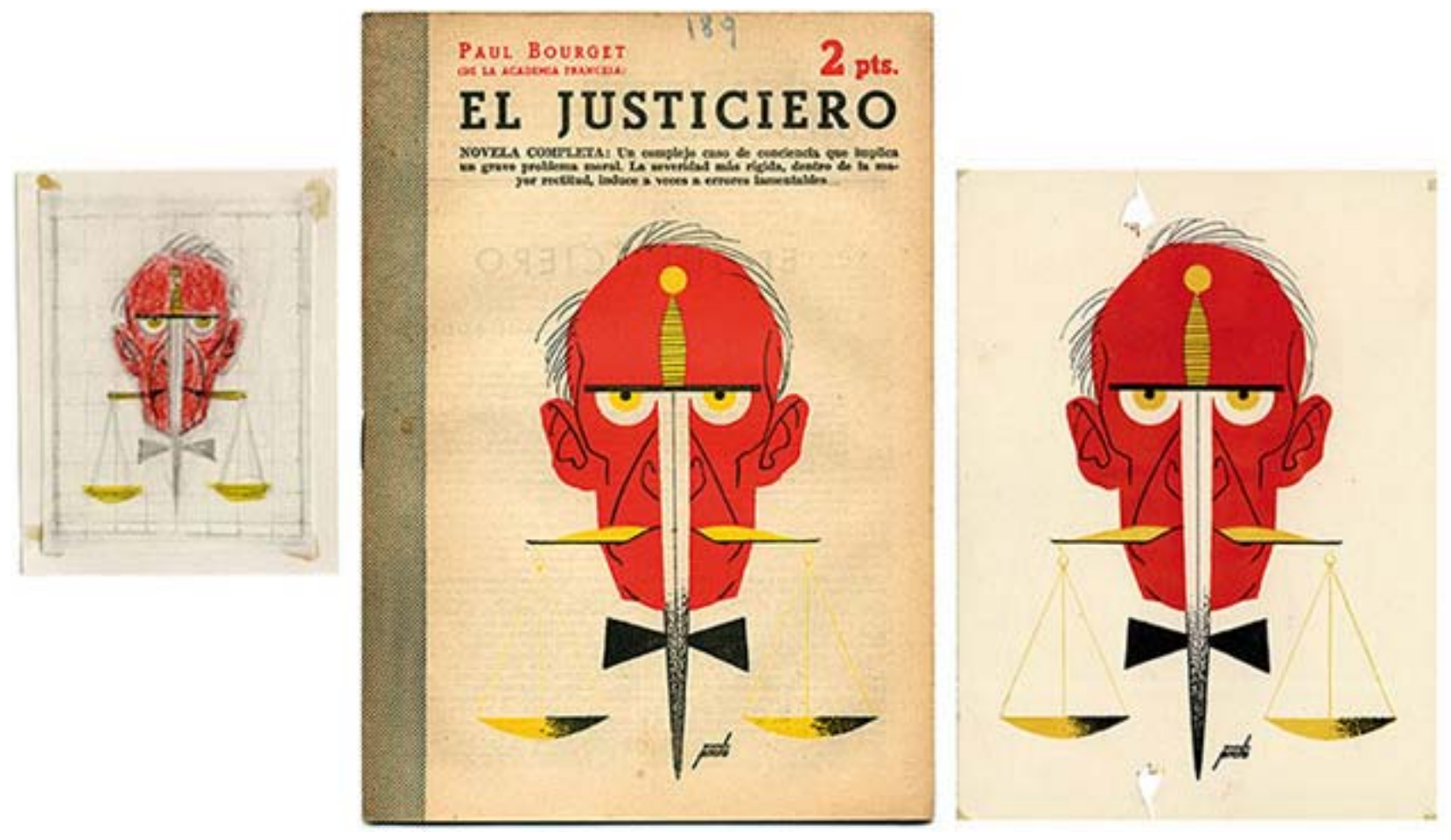

Fig. 1. Boceto, portada y prueba de imprenta de El justiciero, revista no 1170 (11.10.53). 


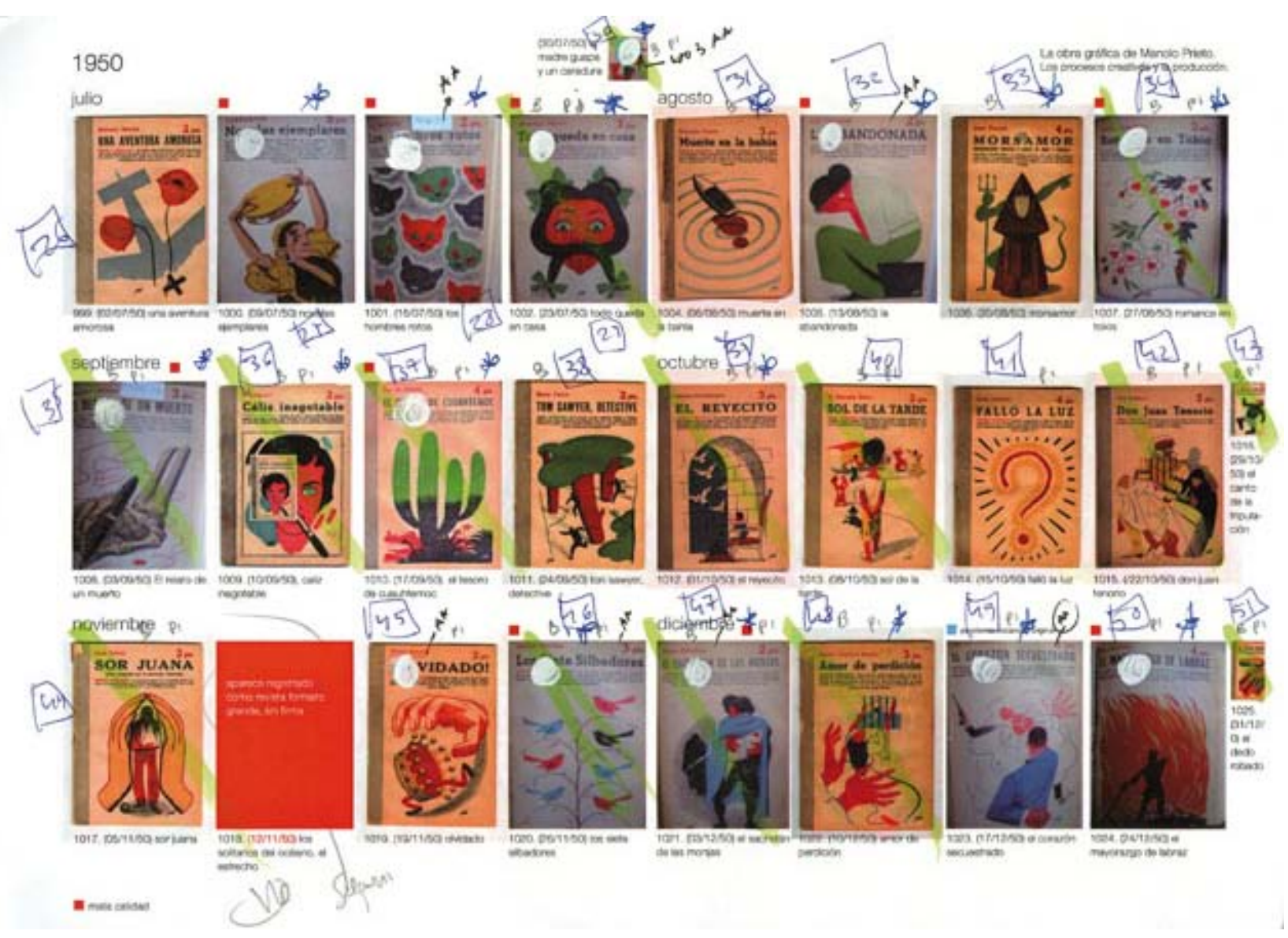

Fig. 2. Ficha de trabajo recopilación portadas Manolo Prieto. Segundo semestre 1950.

\section{Novelas y cuentos}

Novelas y Cuentos es una colección de publicaciones de la literatura universal con firmas de autores reconocidos — tanto españoles como extranjeros $-{ }^{2}$. Una edición que tuvo, desde sus inicios, una difusión extraordinaria.

La editorial Dédalo, inició estas publicaciones en 1929 —el 6 de enero—, finalizando en 1966 con una obra de Benavente ${ }^{3}$. Se llegaron a editar, para entonces, 1842 números. En este periodo también se lanzaron otras publicaciones semanales como La Novela Corta, El cuento semanal, La novela semanal, La novela, Los novelistas o La novela rosa, entre otras.

Esta colección fue impulsada por el periodista y empresario Nicolás María de Urgoiti (1869-1951), e impresa en los talleres de Artes Gráficas Diana ${ }^{4}$. Solo fue suspendida durante la Guerra Civil (desde el 8 de noviembre de 1936 al 28 de enero de 1940) manteniéndose de forma ininterrumpida - todos los domingos - hasta su cierre. Durante los primeros años el formato era de gran folio (23 $\mathrm{cm} \times 31,5 \mathrm{~cm})$. A partir de febrero de 1950 se redujo su tamaño pasando a cuarto $(15 \mathrm{~cm} \times 22,5$ $\mathrm{cm})$. La intención de su editor era utilizar los excedentes de papel de otras publicaciones.

\section{Las portadas}

Manolo Prieto inicia su trabajo como portadista de esta colección en enero de 1940 — con una portada titulada Malasia que se publicaría cuatro años más tarde. Durante estos primeros años los encargos realizados fueron esporádicos. Es, a mediados del año 1944, cuando esta demanda se hace continuada y periódica. Tal situación le obliga —debido a los bajos honorarios recibidos por 
cada uno de los encargos - a tener que reducir las horas dedicadas a cada una de las portadas. Una cuestión que Prieto resuelve sintetizando las imágenes en favor del planteamiento conceptual ${ }^{5}$. Decisión que dejó anotada en su autobiografía:

Cuando me encargaron las portadas de la Revista Novelas y Cuentos, empecé a ilustrar como se ha hecho siempre: buscando la anécdota de un pasaje y haciéndolo por las buenas, pero era tan poco lo que me pagaban, que decidí abaratarlo, dibujando menos y pensando más (porque pensar podía hacerlo mientras paseaba por la calle), y convertí las portadas en carteles de sus propios argumentos ${ }^{6}$.

Tal decisión supuso un giro determinante en la producción gráfica de esta colección. Un cambio en la concepción de este trabajo que, sin duda, influyó de manera determinante en el resto de su producción gráfica (fig. 3).
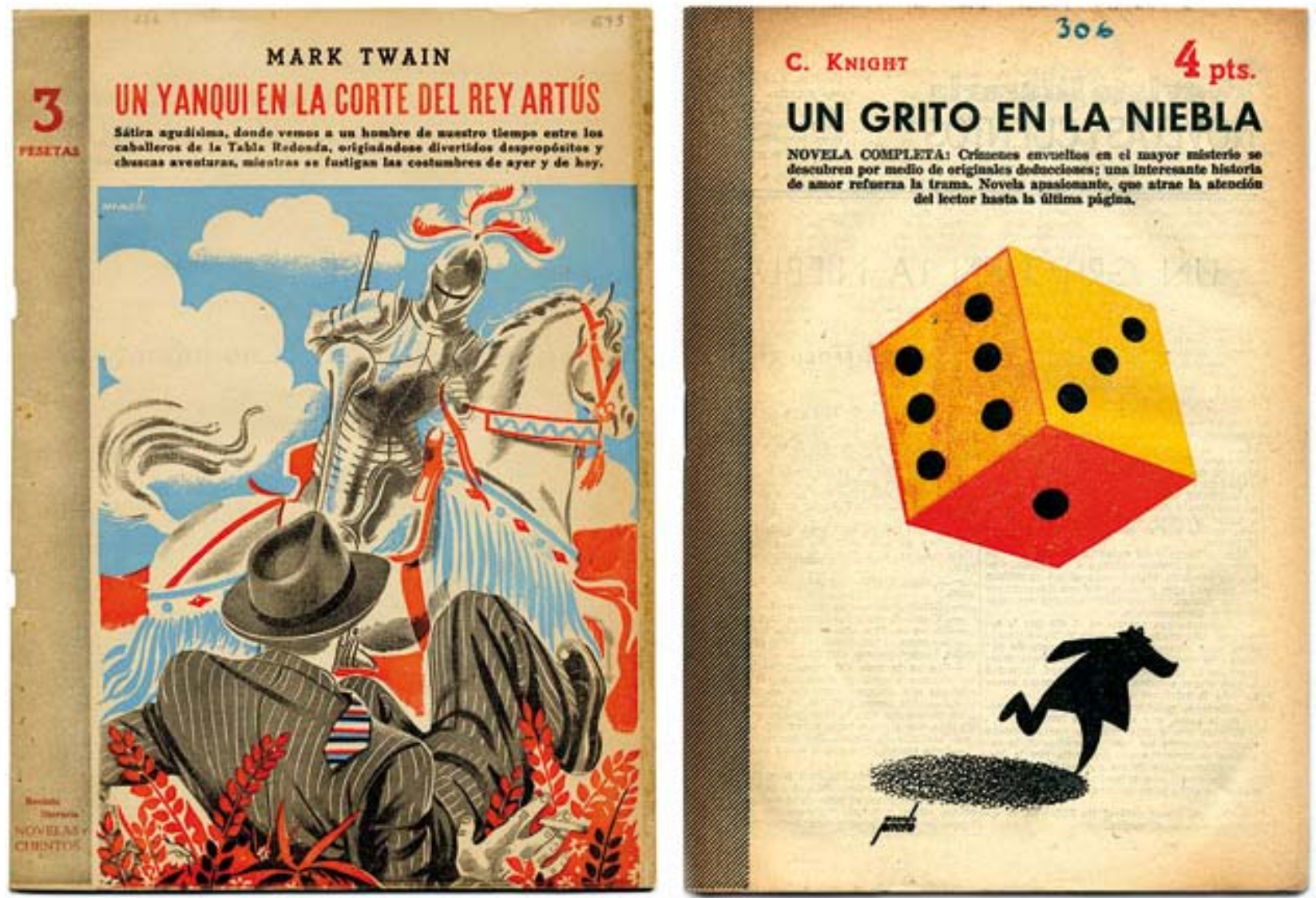

Fig. 3. Portadas Un yanqui en la Corte del Rey Artús, revista núm. 693 (20.08.44) y Un grito en la niebla, revista núm. 1287 (08.01.56).

El conjunto del archivo documental se ordena en dos catálogos, uno correspondiente a las primeras portadas, más laboriosas y complejas gráficamente y un segundo, repleto de ejercicios de síntesis compositiva y de recursos de retórica visual.

El primer catálogo reúne 44 figuras: 39 portadas y 5 artes finales, imágenes que muestran el trabajo inicial de Novelas y Cuentos. Las 39 portadas fueron impresas entre 1942 y 1944. De esta fase sólo se conservan cinco pruebas de imprenta. Además, la información de la que disponemos es bien escasa, apenas la fecha orientativa en muchas de las portadas. 
El segundo catálogo agrupa un total de 1481 imágenes: 578 portadas impresas, 456 artes finales y 457 bocetos. Imágenes que muestran el trabajo más extenso de Manolo Prieto para Novelas y Cuentos, desde abril de 1944 hasta enero de 1959. Con la excepción —tal y como hemos indicado en textos anteriores- de los primeros años, la regularidad en la aparición en la edición semanal de Novelas y Cuentos de portadas ilustradas por Manolo Prieto fue constante. De estos años conservamos una buena cantidad de bocetos y pruebas de imprenta.

Manolo Prieto abordaba la idea a partir de unos primeros bocetos - en muchos casos de pequeñas dimensiones, parecidas a las de un sello de correos-, concebidos sobre la lectura en voz alta que Emilia, su mujer, le hacía de la obra a ilustrar mientras él trabajaba en otros encargos. Explicaba así la razón por la que usaba estos formatos tan pequeños: «el tamaño me impide hacer detalles» ${ }^{7}$. Solo lo elemental tiene lugar, solo lo necesario: no cabe lo prescindible (fig. 4).

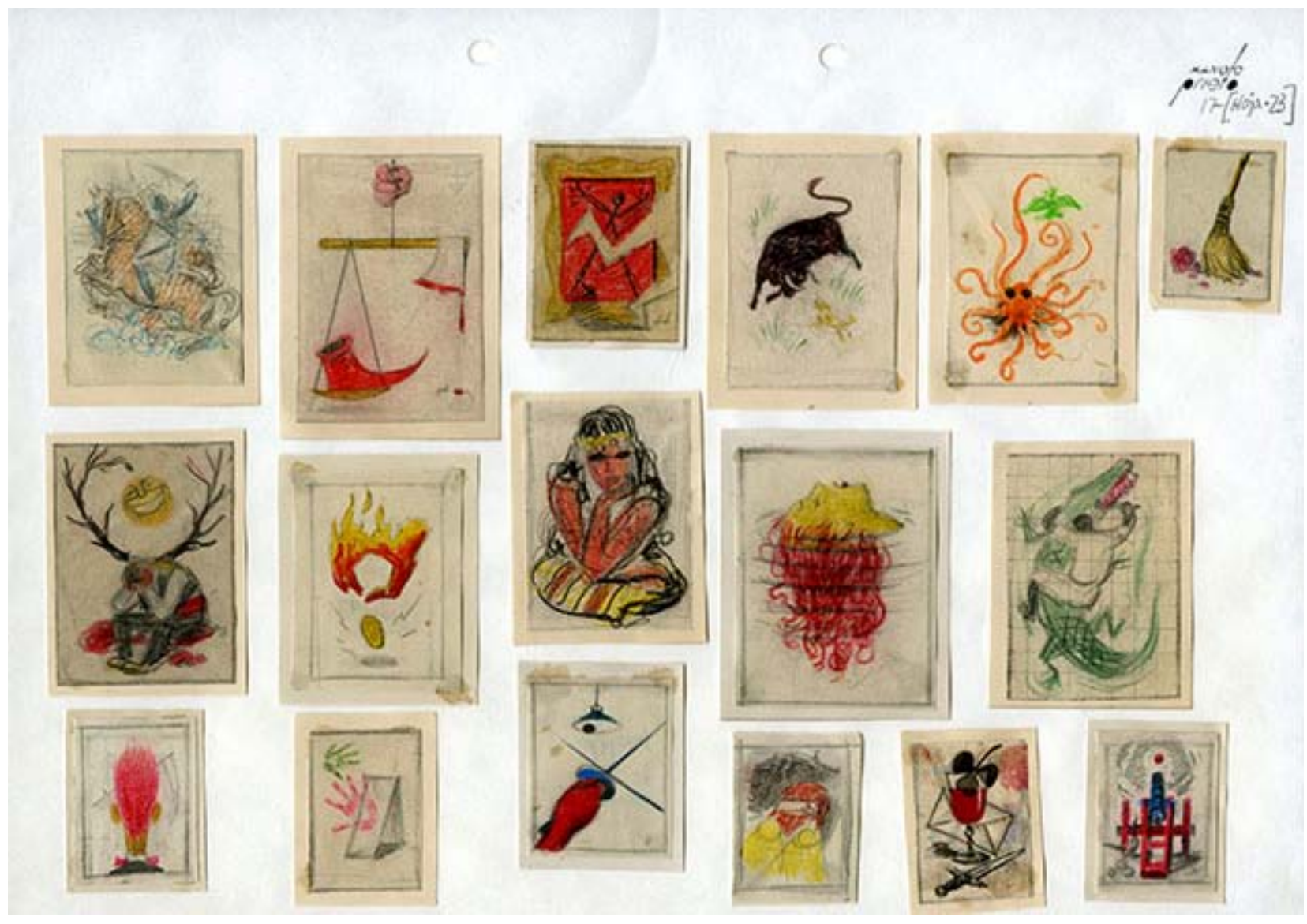

Fig. 4. Ficha recopilación de bocetos de Novelas y Cuentos. Fundación Manolo Prieto.

A lo largo de los 17 años de colaboración y 618 portadas, encontramos un amplio repertorio de soluciones compositivas, «un laboratorio de hallazgos gráficos» en palabras de Francisco Lagares. El conjunto de todo este trabajo (incluidos bocetos, artes finales, pruebas de imprenta y portadas), es un archivo imprescindible para el conocimiento del diseño gráfico en nuestro país (figs. 5, 6, 7, 8 y 9$)$. 

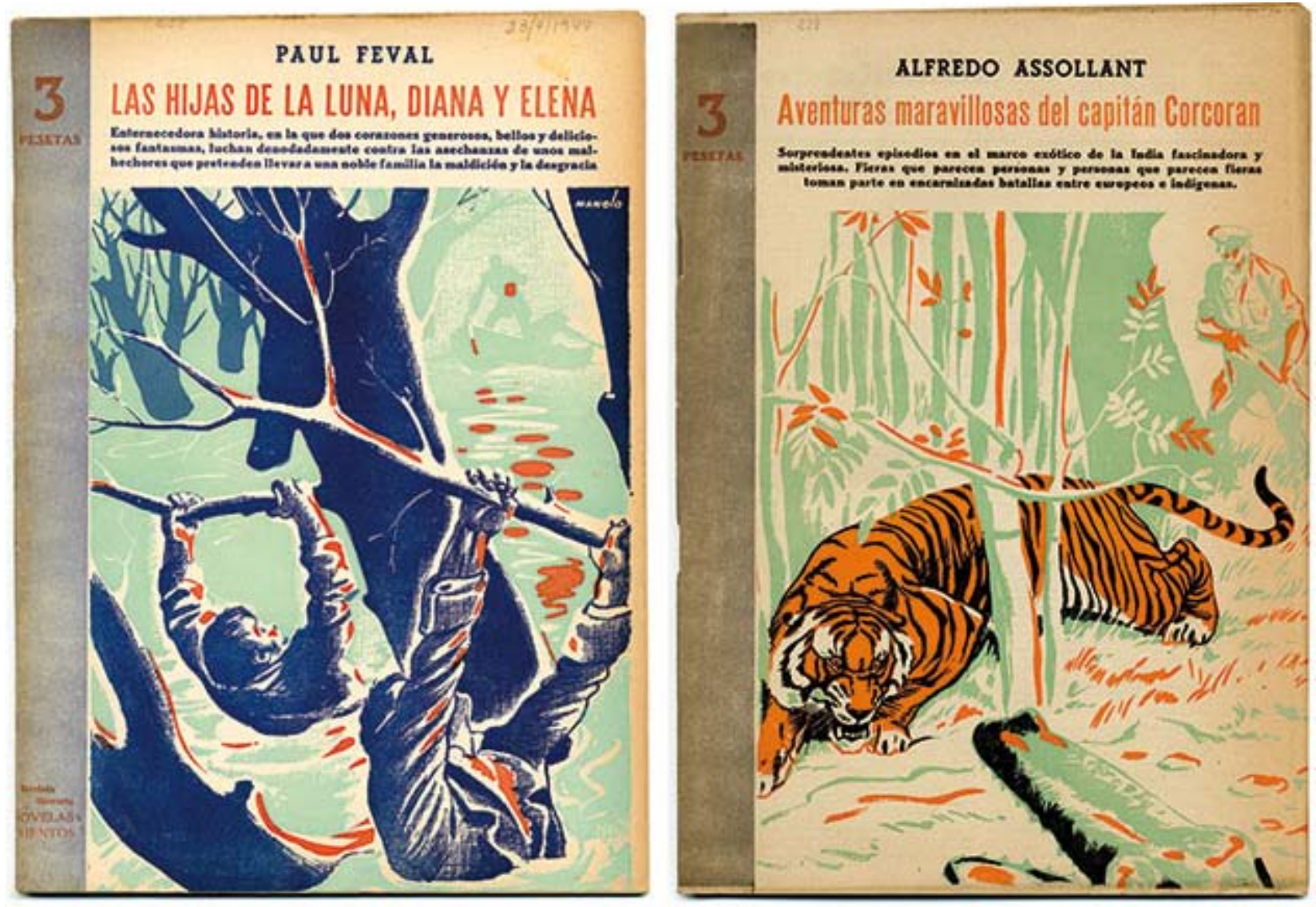

Fig. 5. Portadas Las hijas de la Luna, Diana y Elena, revista núm. 676 (23.04.44) y Aventuras maravillosas del capitán Corcoran, revista núm. 717 (04.02.45).
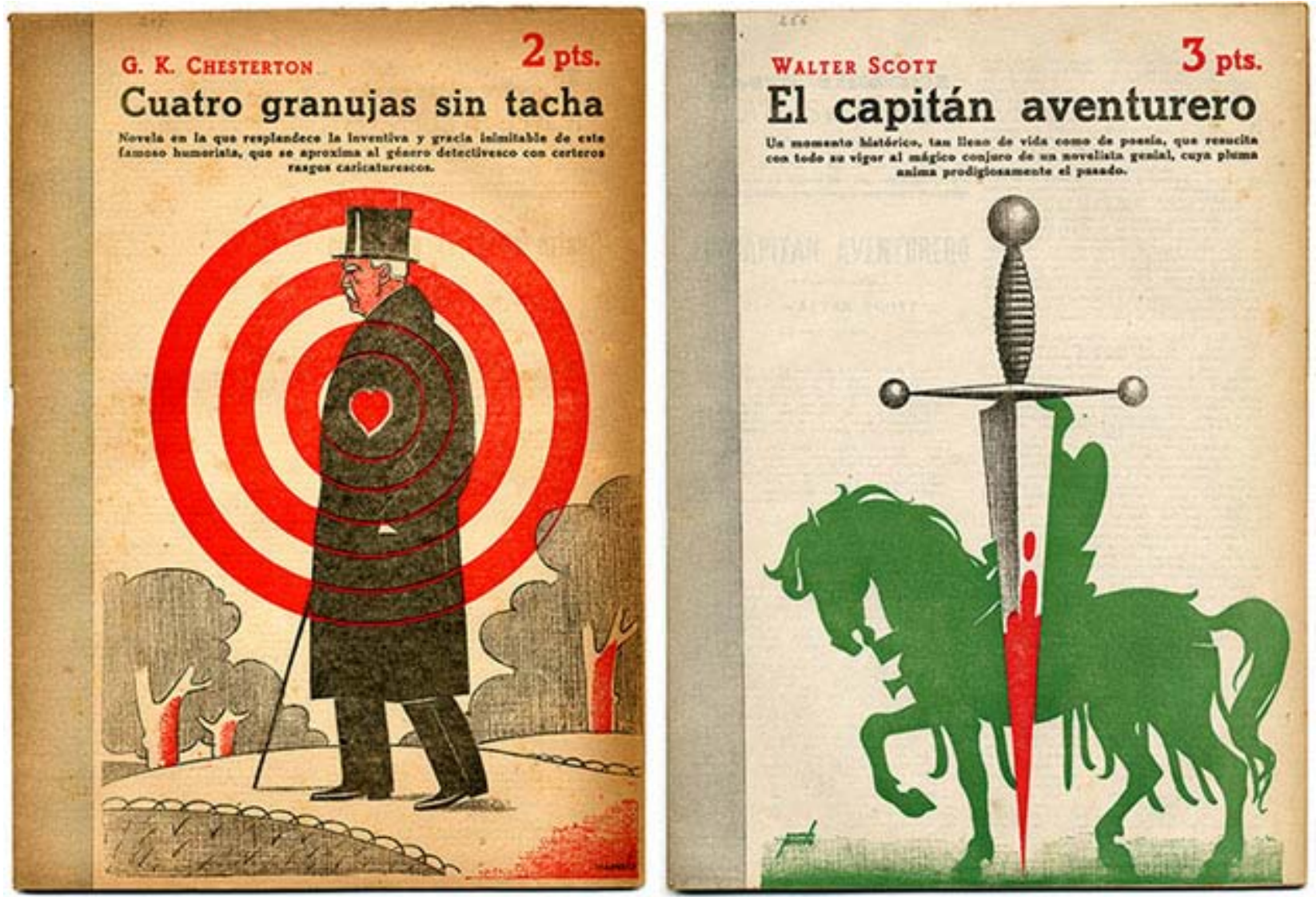

Fig. 6. Portadas Cuatro granujas sin tacha, revista núm. 800 (08.09.46) y El capitán aventurero, revista núm. 810 (17.11.46). 

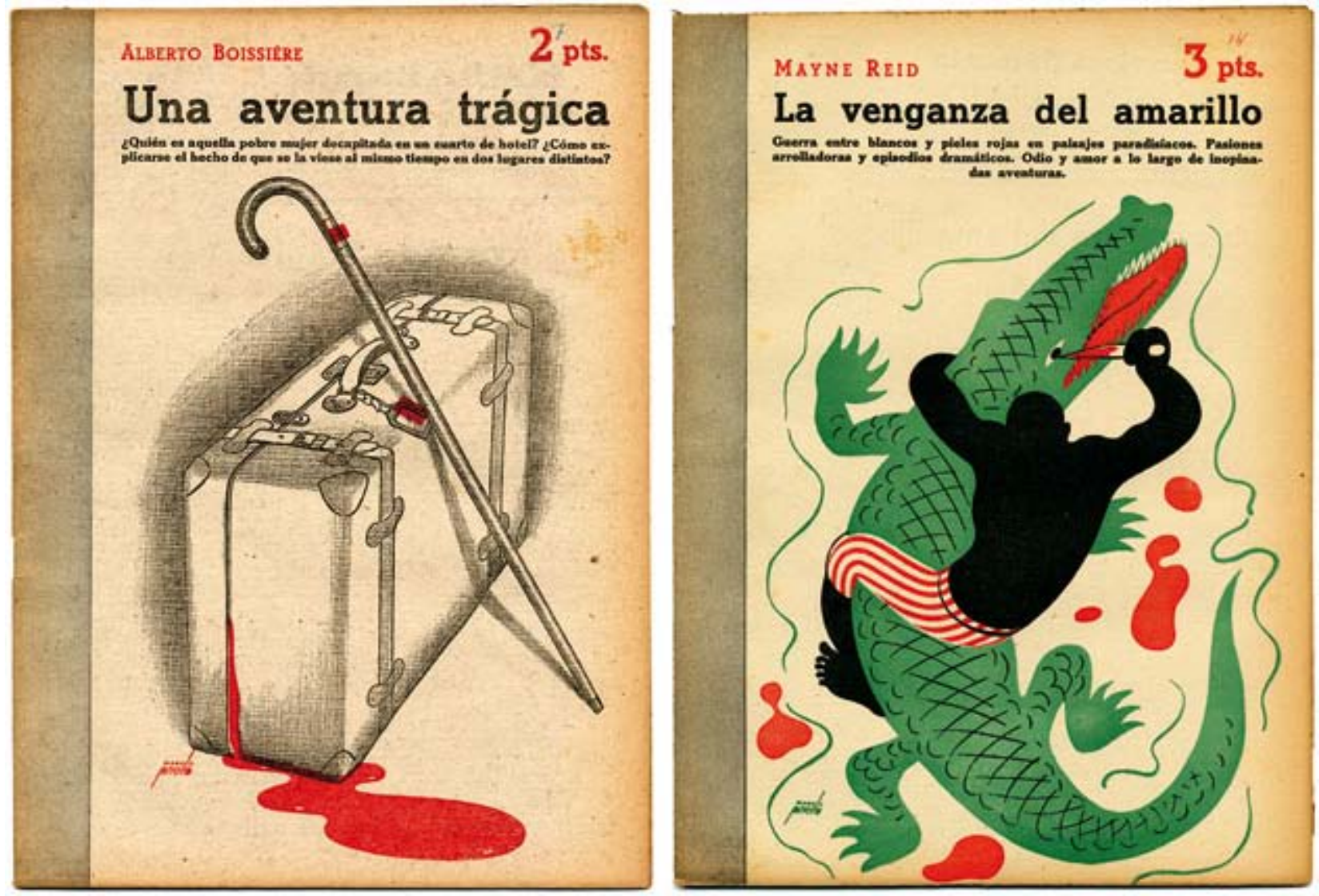

Fig. 7. Portadas Una aventura trágica, revista núm. 871 (18.01.48) y La venganza del amarillo, revista núm. 894 (27.06.48).
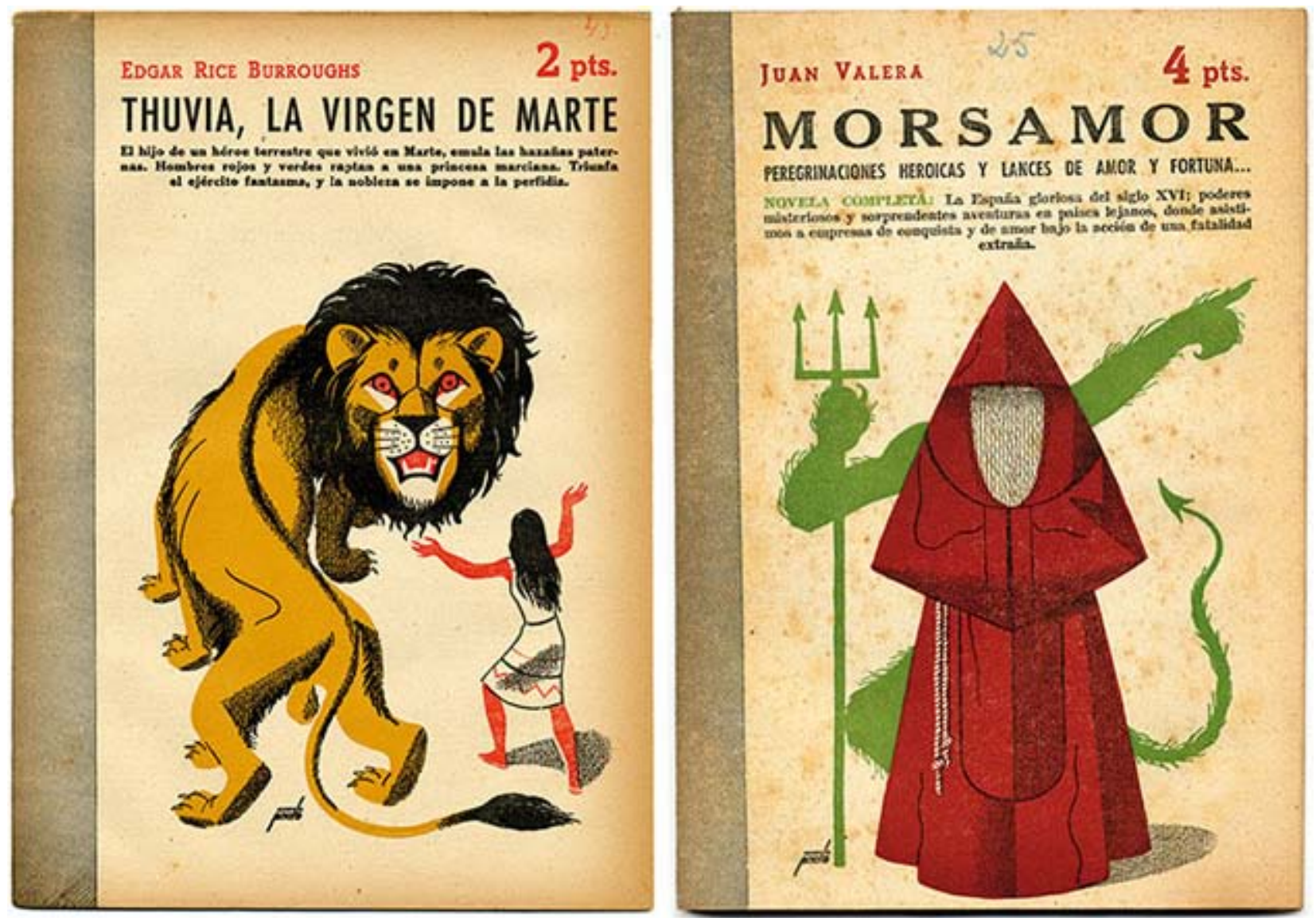

Fig. 8. Portadas Thuvia, la virgen de Marte, revista núm. 963 (29.10.49) y Morsamor, revista núm. 1006 (20.08.50). 

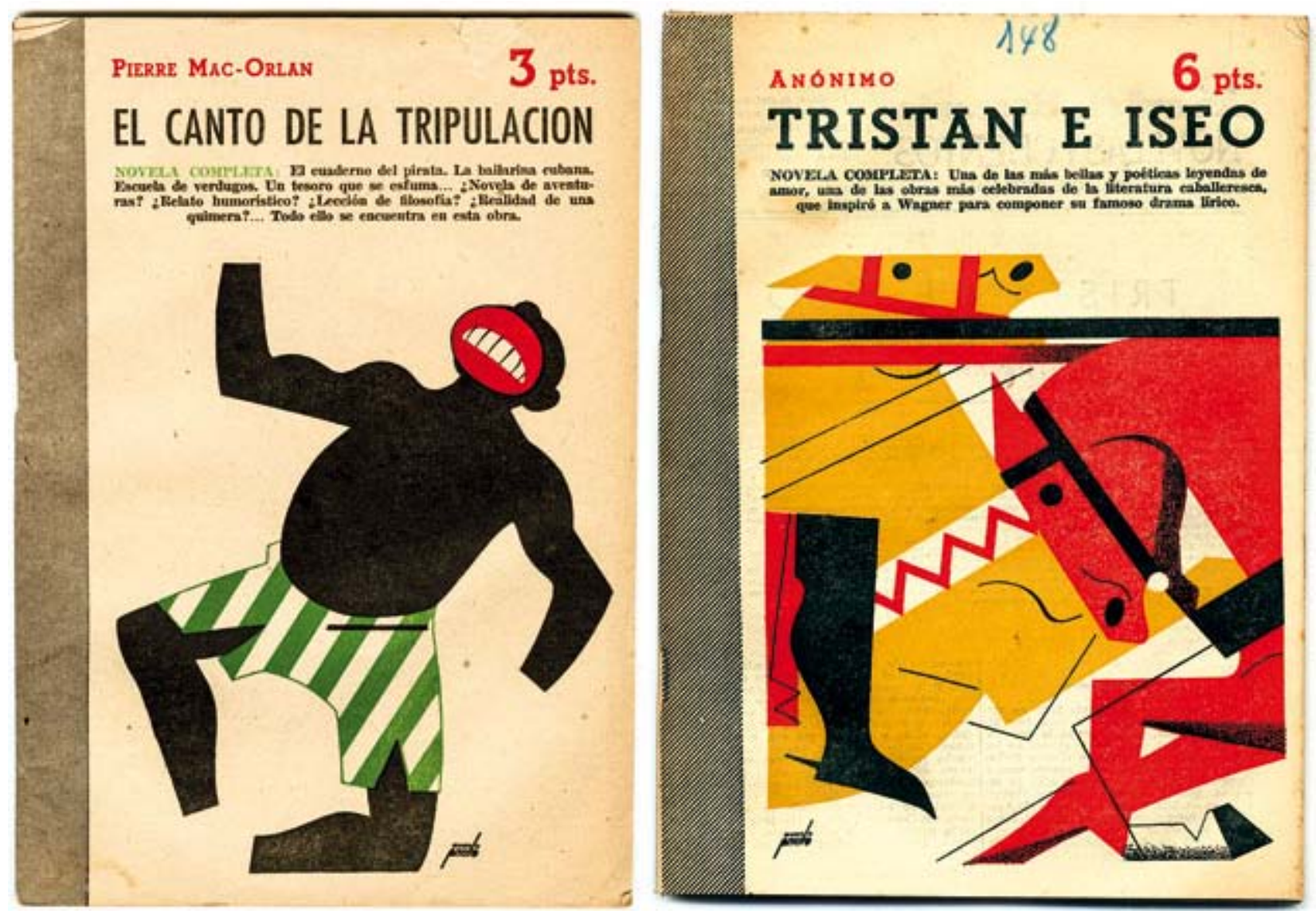

Fig. 9. Portadas El canto de la tripulación, revista núm. 1016 (29/10/50) y Tristán e Iseo, revista núm. 1129 (28.12.52).

Podríamos vincular la manera en la que aborda este trabajo en relación a las características propias del encargo. Al no tratarse de imágenes publicitarias —en el sentido de que no han de representar al producto objeto de venta—, no están en lugar de él ni remiten a él. Los diseños de portadas de esta revista no tienen una finalidad netamente comercial. Es un encargo de trabajo no sometido a los dictados de la comunicación publicitaria y que, por tanto, puede permitir la elaboración de imágenes abiertas —no sujetas a un briefing específico-, propositivas en su interpretación. Así pudo entender Manolo Prieto las posibilidades de experimentación gráfica y artística que este trabajo le podía reportar. En este sentido Novelas y Cuentos fue el germen de un lenguaje gráfico personal.

El conjunto de esta producción gráfica es un compendio de exploraciones formales, formulaciones retóricas y juegos compositivos, más cercano al campo de investigación de las vanguardias históricas que a los dictados de las reglas imperantes de la comunicación publicitaria de estos años.

En enero de 1957, un desacuerdo con el director de la publicación puso fin a este trabajo. Aunque se publicarían tres portadas —1958, 1959 y 1963— diseñadas y entregadas con anterioridad.

La última portada editada — que mostramos por primera vez en esta publicación—, titulada Una Cristiana, se editó el 17 de noviembre de 1963. Aunque, como en otras portadas, no aparece su firma, la Fundación Manolo Prieto si dispone del boceto de esta ilustración corroborando de esta forma su autoría (fig. 10). 


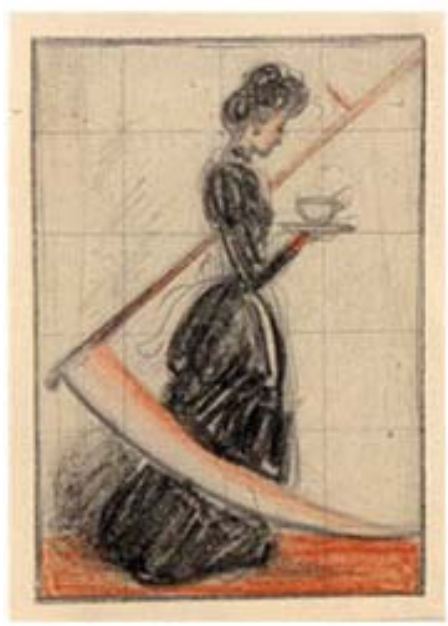

\section{Condesa de Pardo BazÁn 8 pts. UNA CRISTIANA}

Abnegación y heroismo de una mujer que, por no presenciar extravios familla. res, xacrifiea su juventad y renuncia a su felieidad, easindose con un hombre mezgnoino, a quien no puedo amar.

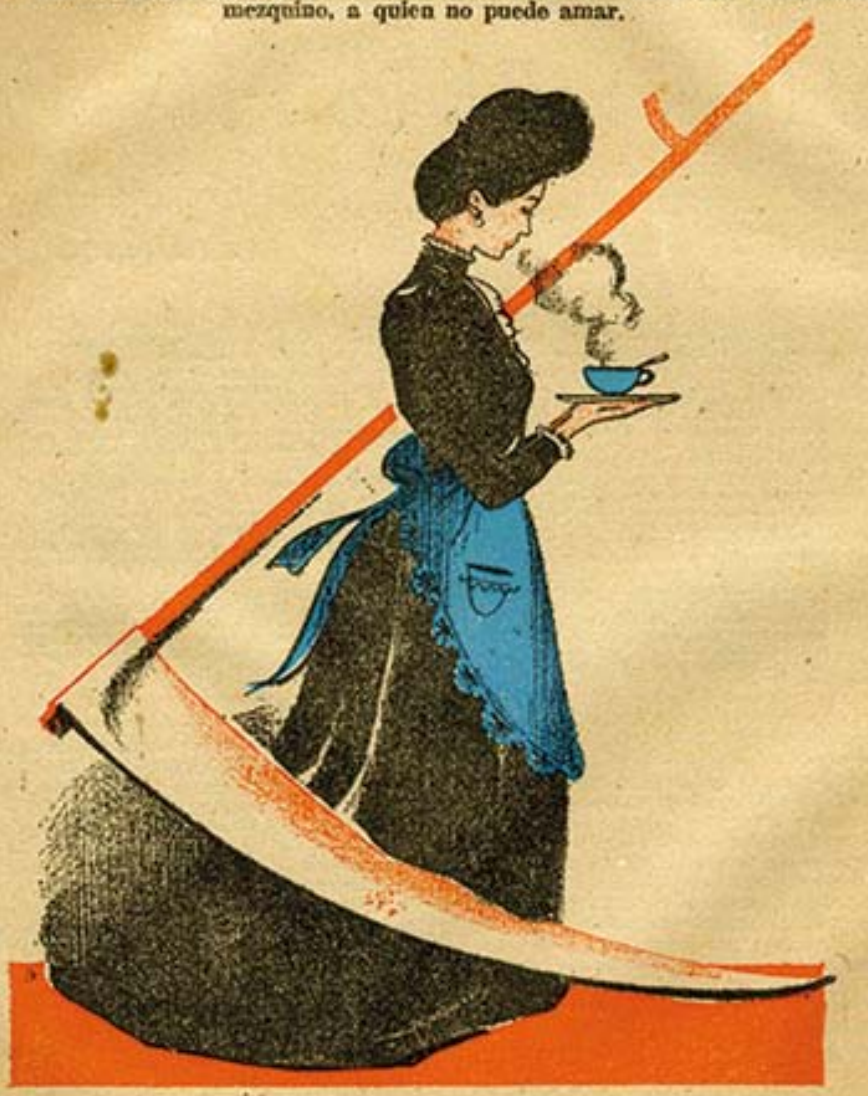

Fig. 10. Boceto y portada revista Una cristiana, número editado el 17 de noviembre de 1963. Seis años después de terminar la relación profesional de Manolo Prieto para la editorial Dédalo. Fundación Manolo Prieto.

En este proceso de análisis y clasificación han sido determinantes los apoyos del investigador Antonio González Lejárraga ${ }^{8}$ —para la elaboración final del listado de ediciones de Novelas y Cuentos, tanto de los títulos como de las autorías de cada portada - y de Abelardo Linares ${ }^{9}$ director de la editorial sevillana Renacimiento y propietario de una importante colección de publicaciones y revistas entre las que se encuentra Novelas y Cuentos - para la correcta digitalización y tratamiento cromático de todas las portadas.

\section{Pruebas de imprenta}

De igual forma que con los bocetos, su hijo Manolo Prieto Rodríguez ha custodiado para su posterior clasificación todos los originales para imprenta con las que cuenta la Fundación. Son aquellas pruebas que el taller de impresión le enviaba para verificar los resultados en cuanto a la calidad del dibujo y la reproducción de los colores (siempre entre una y tres tintas planas). Muchas son las pruebas conservadas y en ellas es posible apreciar el juego cromático con los colores más limpios que sobre el papel final de tirada, siempre de inferior calidad (fig. 11). 

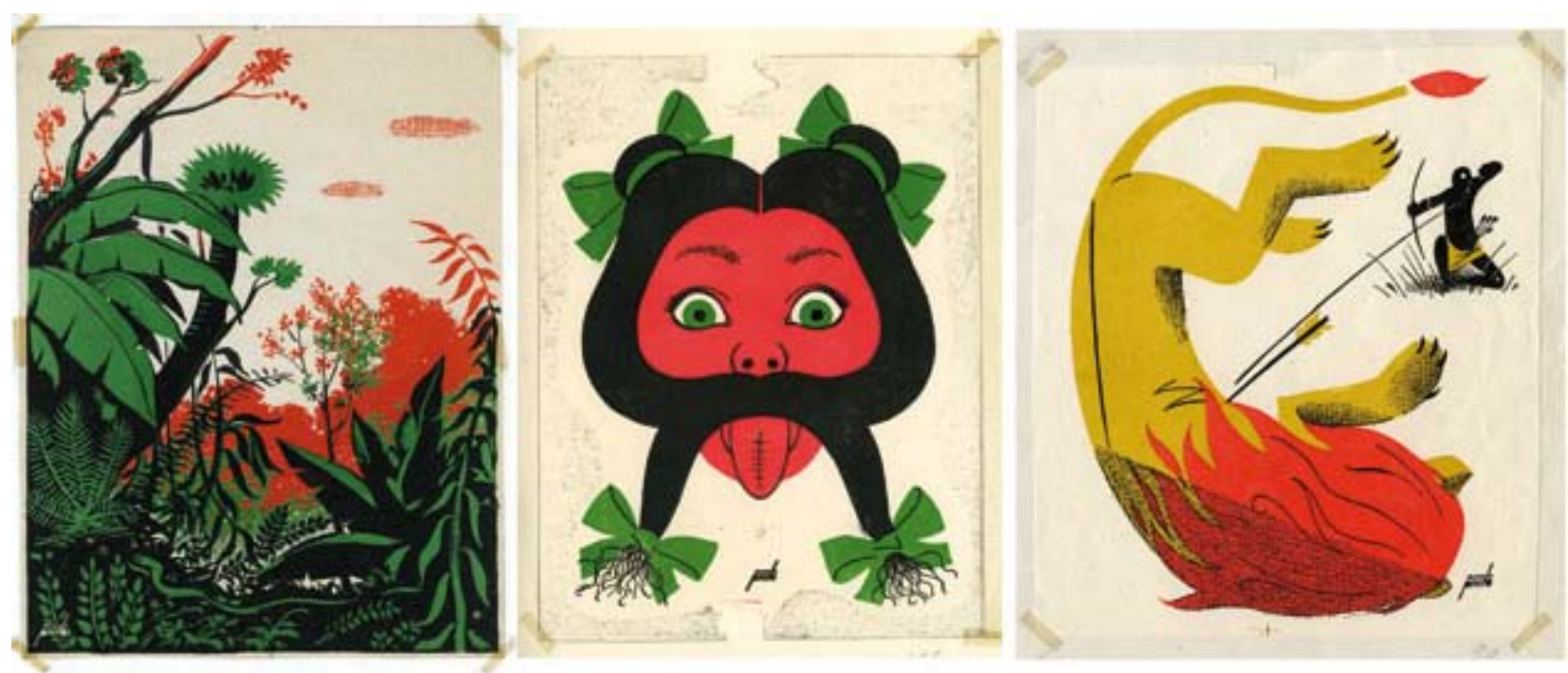

Fig. 11. Pruebas de imprenta para las portadas La atracción de la selva, revista núm. 840 (15.06.47); Todo queda en casa, revista núm. 1002 (23.07.50) y La aguja de oro, revista núm. 1332 (18.11.56). Fundación Manolo Prieto.
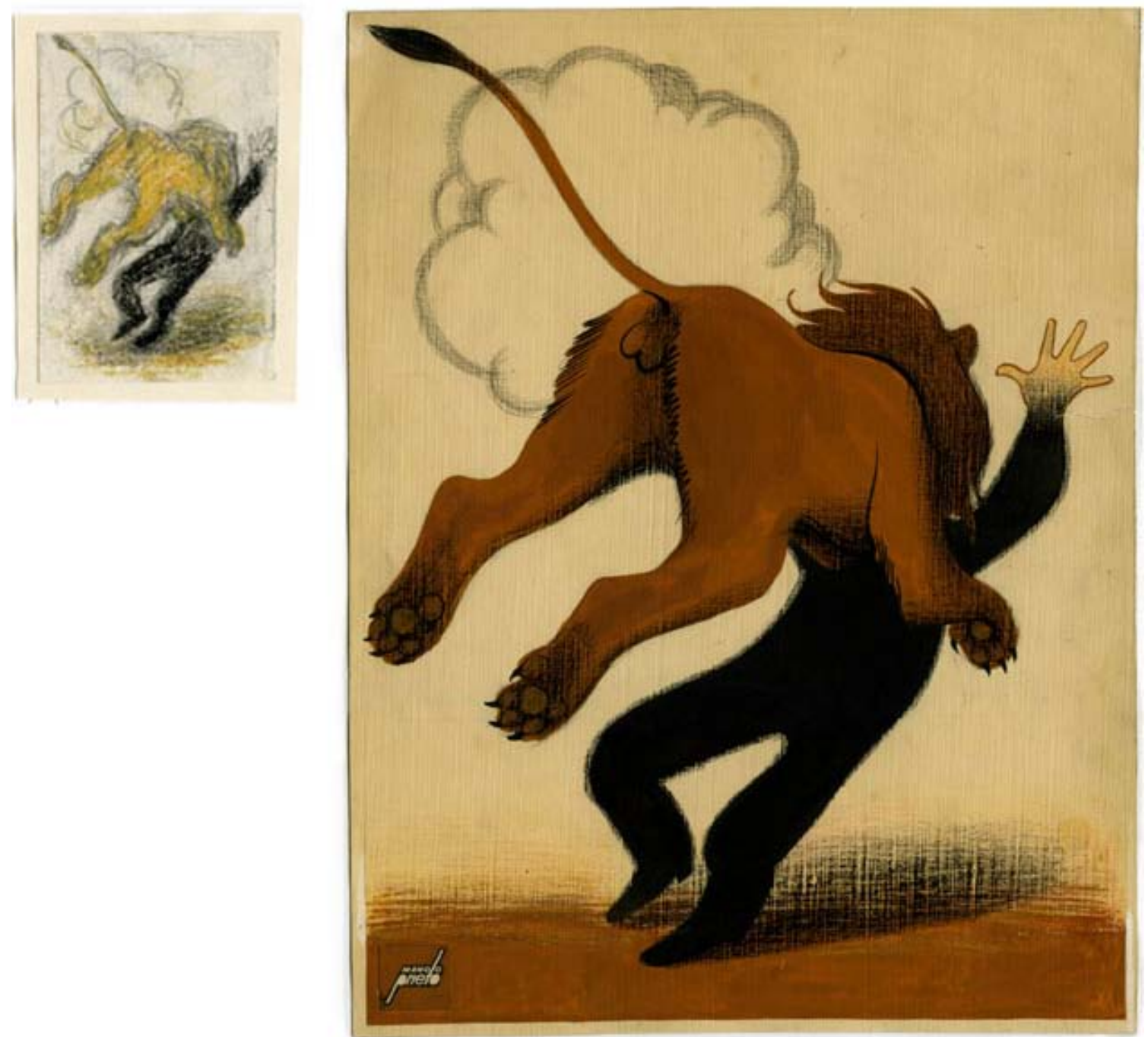

Fig. 12. Boceto y arte final para la portada Clovis Dardentor, revista núm. 812 (01.12.46). Finalmente se editó esta portada con otra ilustración, habiendo ya realizado este arte final. Las razones de este cambio (como en otras portadas) pudo deberse al requerimiento de la editorial o a la decisión de Manolo Prieto de mejorar la composición. Archivo de la Fundación Manolo Prieto. 


\title{
Artes finales para producción
}

La colección de los escasos originales para imprenta están elaborados sobre papeles gruesos y texturizados (como los utilizados para óleo o acuarela) con diversas técnicas de lápiz, recurriendo al lápiz litográfico para las texturas y frottages aplicados y variados colores. La Fundación Manolo Prieto conserva nueve artes finales para impresión. Resulta una muestra anecdótica, tomando en consideración la enorme cantidad de portadas realizadas para Novelas y Cuentos (fig. 12).

\section{Manolo Prieto}

De esta manera comienza Manolo Prieto su autobiografía — resumida en unas cinco páginas a modo de testimonio - escrita a los 68 años de edad. Un autorretrato, a veces en clave humorística, en el que nos relata las circunstancias que rodearon su vida personal y profesional hasta 1978:

\begin{abstract}
Me nacieron en El Puerto de Santa María (Cádiz) un día 16 de Junio de 1912. Mi madre me contaba que en aquel momento pasaba por la esquina de mi casa una Procesión, a la que tan dadas son aquellas tierras de María Santísima. Único sobrino varón entre muchas tías, me despertaron un mal genio fenomenal, yo creo que debido al mucho besuqueo. Mis primeros recuerdos son los de limpiarme la cara con un manotazo cada vez que me llenaban de besos los carrillos ${ }^{10}$.
\end{abstract}

La inquietud por el dibujo surgida en su infancia lo llevó a ingresar en la Academia de Bellas Artes de Santa Cecilia, donde cursó estudios de dibujo y pintura con el profesor Juan Bottaro. Estos estudios fueron determinantes en su vocación como pintor. Viajó a Madrid para continuar su formación. Acuciado por las circunstancias económicas comienza una actividad profesional que lo llevará al campo del arte gráfico y la publicidad. En escasos dos años consigue cierta estabilidad económica y profesional gracias a su trabajo en Publicitas, agencia de publicidad filial española de una agencia matriz suiza, dirigida entonces por el ilustrador y editor Emeterio R. Melendreras ${ }^{11}$, con quien mantendrá una estrecha relación profesional y colaborará intensamente en la revista Arte Comercial —de la que éste era editor- en los años posteriores.

Es a partir el año 1940 cuando comienza a ilustrar la revista literaria Novelas y Cuentos, publicación semanal muy económica pero con gran relevancia por sus portadas simbolistas y novedosas. Desde mediados de los años cuarenta hasta finales de la siguiente década Manolo Prieto desarrollará la mayor parte de su trabajo gráfico y publicitario. Cabe señalar que, gran parte del mismo, en su otra actividad como director artístico en la Agencia Azor, donde fue contratado en 1947, y para la que hará las campañas publicitarias más importantes, entre las que podemos destacar la famosa valla del Toro Osborne.

El análisis en torno a su obra gráfica —en general— es un recorrido a través de diferentes estilos, un compendio de recursos gráficos y visuales a disposición del mensaje publicitario y un ejercicio de composiciones que admite nuevos modelos de representación formal.

*Docente y diseñador gráfico. Doctor en Bellas Artes por la Universidad de Málaga, 2015. Profesor Asociado Facultad de Bellas Artes de Málaga, Universidad de Málaga. Correo-e: juan@estaciondiseno.es 
1 AGUILAR, Juan. Manolo Prieto. Las portadas de Novelas y Cuentos. Los procesos creativos y la producción gráfica. Universidad de Málaga, Tesis doctoral, 2015.

2 TRAPIELLO, Andrés. Imprenta moderna: tipografía y literatura en España, 1874-2005. Editorial Campgràfic, Valencia 2006, p. 290.

3 TRAPIELLO, A. Ibidem, p. 279.

${ }^{4}$ CABRERA, Mercedes. La industria, la prensa y la política. Nicolás María de Urgoiti (1869-1951). Alianza Editorial, Madrid 1994.

5 En respuesta al artículo «Las portadas de Novelas y Cuentos de Manolo Prieto», que publicamos en pionerosgráficos.com — blog del diseñador Emilio Gil sobre el trabajo de los diseñadores gráficos españoles desde 1939 (final de la Guerra Civil española y comienzo de la Segunda Guerra Mundial) hasta 1975 (año de la muerte del General Franco y comienzo de la democracia en España)—, Albert Culleré (02.07.2015) hacía la siguiente reflexión sobre este hecho «[...] Paseando se concentraba en lo fundamental, ya que "pensar es esquematizar" (Edmond Goblot 1858- 1935), y así ninguna figura o concepto preconcebido le distraía. En el momento de plasmar lo pensado, el recurso del micro boceto le permitió eludir lo superfluo y encontrar la voluntad de la forma en la voluntad de la idea». Pioneros Gráficos [en línea] http://pionerosgraficos.com/2015/06/las-portadas-de-novelas-y-cuentos-demanolo-prieto/ (19.08.2015).

${ }^{6}$ Fundación Manolo Prieto [en línea] http://www.fundacionmanoloprieto.org/contenidos/vida_obra.htm (27.08.2015).

${ }^{7}$ Extracto de su Discurso de Ingreso en la Academia de Santa Cecilia. Fundación Manolo Prieto [en línea] http://www.fundacionmanoloprieto.org/contenidos/vida_obra.htm (27.08.2015).

${ }^{8}$ Autor de numerosos artículos, centrados en la ilustración editorial y sus creadores del período anterior a la Guerra Civil. También ha publicado en el CSIC el libro La Novela Rosa en la colección Literatura Breve en España y próximamente, también en esta colección se publicará Biblioteca Oro de Editorial Molino, escrito con Fernando Eguidazu.

${ }^{9}$ Espejos. Es director de la Librería y Editorial Renacimiento. La compra de la colección del librero gallego Eliseo Torres en Nueva York, le supuso —en el diario El País— el apelativo de «el hombre del millón de libros». El País [en línea] http://elpais.com/diario/2010/08/12/revistaverano/1281564005_850215.html (19.08.2015).

${ }^{10}$ Fundación Manolo Prieto. [en línea] http://fundacionmanoloprieto.org/contenidos/vida_obra.htm(25.08.2015).

${ }^{11}$ Eguizábal, Raúl. «Emeterio R. Melendreras». Articulo publicado en la revista Publifilia, nº 7, Junio 2003. [en línea] http://www.academiadelapublicidad.org/portfolio/emeterio-r-melendreras-2/ (13.04.2015).

\section{BIBLIOGRAFÍA}

EGUIZÁBAL, Raúl. El cartel en España. Ediciones Cátedra, Madrid 2014.

GARCÍA, Francisco. Historia de la publicidad en España. Mundo Científico, Madrid 1971.

GIL, Emilio. Pioneros del diseño gráfico en España. Index Book, Barcelona 2007.

GONZÁLEZ, Antonio. La novela rosa. Madrid. Consejo Superior de Investigaciones Científicas (CSIC), Madrid 2011.

HELLER, Steven/GODFREY, Jason. 100 revistas clásicas de diseño gráfico. Ediciones Blume, Barcelona 2014.

JARDÍ, Enric. Pensar con imágenes. Editorial Gustavo Gili, Barcelona 2012.

MARAVALLI, José Luis. La edición crítica como metodología para la reproducción digital de imágenes impresas policromas. Las portadas diseñadas por Manolo Prieto para la revista literaria Novelas y Cuentos. Universidad Miguel Hernández de Elche, Departamento de Arte de la Facultad de Bellas Artes, Elche 2014.

MARTÍNEZ, Jesús Antonio. Historia de la edición en España 1939-1975. Ediciones de Historia, Madrid 2015.

Ríos, Sonia. La crítica de diseño gráfico en la revista Arte Comercial (1946-1952). Textos Mínimos, Universidad de Málaga, 2007.

ROBERTS, Caroline. Visionarios del diseño gráfico. Ediciones Blume, Barcelona 2015.

SATUÉ, Enric. El diseño gráfico en España. Desde los orígenes hasta nuestros días. Alianza Editorial, Madrid 1998.

TRAPIELLO, Andrés. Imprenta moderna: tipografía y literatura en España, 1874-2005. Editorial Campgràfic, Valencia 2006. 


\section{Catálogos}

Facetas Artísticas de Manolo Prieto. Fernando Pérez Mulet Ediciones, El Puerto de Santa María 2004.

Grafistas. Diseño gráfico español 1939-1975. Secretaría General Técnica. Subdirección General de Publicaciones, Información y Documentación, Madrid 2001.

Manolo Prieto y el Toro Osborne. Editorial España Abierta, El Puerto de Santa María 1995.

Signos del siglo. 100 años del diseño gráfico en España. Madrid, ddi (Sociedad Estatal para el Desarrollo del Diseño y la Innovación). Dirección General de la PYME. Ministerio de Economía y Hacienda, Madrid 2000.

\section{Revistas}

Arte Comercial. Año 1, núms. 1-40. Madrid 1846/1952.

"25 años de diseño gráfico español 1970-1995". Suplemento del número 13/14. Experimenta, Madrid 1996.

\section{Fuentes digitales}

Fundación Manolo Prieto [en línea] http://fundacionmanoloprieto.org

Pioneros Gráficos. «Las portadas de Novelas y Cuentos de Manolo Prieto» [en línea] http://goo.gl/wohsJ3

Revista internacional de investigación, innovación y desarrollo en Diseño • ISSN 1889-433 x

Grupo de investigación Lenguaje Visual y Diseño Aplicado • Plan Andaluz de Investigación • E. Politécnica S. • Universidad de Málaga 